\title{
HiQ International Company: A Case Study of Operational Effectiveness post Merger and Acquisition
}

\author{
Belle Selene $\mathrm{Xia}^{1}$ \\ ${ }^{1}$ Department of Economics and HECER, University of Helsinki, Helsinki, Finland \\ Correspondence: Belle Selene Xia, Department of Economics and HECER, University of Helsinki, P.O. Box 17 \\ (Arkadiankatu 7), FI-00014 Helsinki, Finland. E-mail: selene.xia@live.com
}

Received: January 10, 2014

Accepted: January 21, $2014 \quad$ Online Published: March 1, 2014

doi:10.5430/ijba.v5n2p60

URL: http://dx.doi.org/10.5430/ijba.v5n2p60

\begin{abstract}
Mergers and acquisitions occur in a dynamic process in which resource allocation and organization structures are restructured in response to new challenges. Analyzing mergers and acquisitions in the technology sector using the empirical case of HiQ International $\mathrm{Ab}$ shows that management efficiency post merger and acquisition requires the reallocation of resources where traditions and culture are broken resulting in numerous side effects of change. In addition, the management morale in the business world may significant differ from what was assumed in the traditional literature on this subject matter. As a matter of fact, if profit maximization is one of the key motives of the acquirer firm, this is often driven by differing incentives that, nevertheless, govern the dynamic process of M\&A. Consequently, the benefits of M\&A may be greatly reduced due to the management conflicts between the acquiring and the target firm. In this study, we analyze successful acquisitions based on little asset divestiture even in the case of high strategic similarity. We propose an alternative business framework to view M\&A given the nature of consulting-based software companies. Consequently, the difference of product-based software companies, as opposed to consulting-based software companies, may employ contrary attitude towards the integration of the target firm. Our study also opens future research opportunities for mergers and acquisitions of international companies in the technology sector. (Note 1)
\end{abstract}

Keywords: mergers and acquisitions, management efficiency

\section{Introduction}

Our research aims to evaluate the operational effectiveness of mergers and acquisitions (M\&A) in HiQ International $\mathrm{Ab}(\mathrm{HiQ})$ with special focus on HiQ Finland in order to compare the results with the traditional literature done on this subject matter. This analysis is primarily based on HiQ's historical data and insights from the employees who witnessed the acquisitions. In addition, the author also has the working experience in $\mathrm{HiQ}$ as an Integration Consultant in one of HiQ's target firms before the M\&A activity in the year 2010. The purpose of this research is to identify the lessons that can be learnt from M\&A using an empirical case. We will compare the various strategies employed during the different phases of M\&A through cost-benefit analyses. We will also propose new insights for future M\&A activities for similar consulting-based software companies. Our research results are especially pertinent to M\&A literature relating to resource allocation and asset divestiture in M\&A. We believe that profitable firms may be equally attractive as the target firm compared to unprofitable ones. Specifically, we focus our research on HiQ International $\mathrm{Ab}$ and compare its $\mathrm{M} \& \mathrm{~A}$ activities in the Nordic countries with each other in order to identify a pattern.

The data used in this research stems from the international literature on M\&A. Moreover, various case studies in the past done on M\&A act as benchmark for our analysis. Nevertheless, we will be focusing mostly on company-specific information to quantify trends and evaluate the process through which M\&A either gained success or did not reach its initial goals. The time frame is narrowed to periods when M\&A occurred during the twenties in HiQ, and hence leaving out years before the company is officially listed in 1999. The scope of this research shall also touch upon the subjects of growth, profit and motives of M\&A.

We have organized this paper to facilitate reading. We begin our subsequent study by discussing related concepts of M\&A from the traditional literature that will be compared and contrasted with our company case. This is important in linking theories with practice. Then, we will be elaborating the company under focus by discussing its culture, 
history, background, performance and vision of HiQ. Thereafter, based on the analysis, a new business framework will be built for similar software companies to support future activities in M\&A. Finally, we will be evaluating this new framework, our research approach and summarizing insights in the final sections to end up the discussion.

\section{M\&A Activities in Product-Based and Consulting-Based Company}

The global trend, such the technological advancement, has posed threats to the existing business operation of many international companies in the IT industry putting pressure for them to grow and exploit the possibility of scale economies. Whether as strategies for growth or profit maximization with better resources, it seems that successful M\&A also encourage future M\&A activities. (Gregor et al., 2001) In order to respond to the industry competition, software companies often aim to build their positions as market leaders. This brings the importance to view the various approaches to M\&A that would generate positive cash flows for the acquirer firm. Most importantly, this necessitates improvements in management efficiency of both the acquirer firm and the target firm.

The optimal allocation of resources following M\&A is often discussed using the scale efficiency theory. (Grossman and Helman, 2004) The physical resources as well as the organizational structure undergo important changes as a result of the union. The M\&A process entails reorganization of these resources including the manpower to a new level in order to maximize benefits of the acquisition. In fact, the research work done by Gilmour (1973) and Weston (1994) has shown evidence for the relocation of resources as an integrated part of M\&A. Nevertheless, strategies to manage the target firm have been little empirically confirmed due to the lack of data. Given that M\&A has a long term impact both on the acquirer and the target firm, the executive policies from the top management have a decisive role in determining the aftermath of M\&A. In addition, the business dynamics of M\&A involves multi-faceted players interacting together at the same time resulting in various side effects of change that should be carefully evaluated empirically.

Scholars that agree to the shutdown of factories and the need to reduce work force as a result of M\&A argue that management efficiency requires the disposal of redundant assets and human capital in order to gain sense from the change (Moesel, 1994 and Bergh, 1997). Given the motive for scale efficiency, the sale of the target firm's existing businesses is justified on the base of cost reduction. Given the nature of M\&A, they also believe that change in the form of asset divestiture would occur inevitably as a result of M\&A. This process, then, would be dependent on the feel of the management board of the acquirer firm in how the resource should be allocated in response to the strategic similarities between the acquirer and the target firm. However, we believe that this type of approach to M\&A may be typically seen in a product-based company. In the case of $\mathrm{HiQ}$, being a consulting-based software company, the motive for acquisitions may be of a different kind.

According to Galunic and Eisenhardt (1996), the goal of M\&A is to combine the strengths of both firms in face of industry competition. The redeployment of existing assets would allow the acquirer firm to attain the benefits of the target firm. Capron et al., (1998) also showed how resource allocation in M\&A entails change management. Here, resources include all tangible and intangible assets of the target firm. In case of a consulting-based company, we will illustrate through the empirical case of HiQ how asset divestiture may not always offer the best solution to change management post M\&A. The resource allocation, admittedly, will entail a new management perspective depending on the nature of the company in question.

The target firm often has relatively weaker bargaining power than the acquirer firm, making them easy targets of acquisition. (Su et al., 2010) Unsuccessful M\&A is a financial burden to the acquirer firm. The debt that is required as part of the investment to M\&A is by nature risky. Consequently, many companies finance their acquisitions through cash and issuing new shares. (Nishihara and Shibata, 2010) This is also the case with HiQ. The incentive for M\&A, on the other hand, may be motivated by conflicting managerial incentives. Consequently, the plan of M\&A may shift to a personal struggle for power instead of a strategic decision that benefits the shareholders.

We suggest that the acquirer firm views the target firm as an independent player in the industry that has identity on its own. That is, the management efficiency of the target firm is an asset that could be actualized by the target firm. Due to a lack of transparency, the acquirer firm might be tempted by asset divestiture as a short-term profit maximization strategy. (Lakshman, 2011) However, the goals of asset divestiture may conflict with the goals of M\&A in a consulting-based company. For example, a company might choose to divest if the business cannot be aligned with its core operation. (Weber et al., 2011) However, one of the important reasons for M\&A is to combine the core businesses of the acquirer and the target firm in order to expand the product offerings of the new company in the software industry. Economies of scale would also suggest the benefit of a large size. 


\section{Research Objectives and Methodology}

This study employees company data, comparison study and in-depth interview research that aims to gain a better understanding of resource allocation that would increase management efficiency post M\&A. Since HiQ had frequent M\&A activities in the twenties, it would be interesting to also compare the performance of these target firms before, during and post M\&A. Moreover, we aim to formulate strategies that would support future M\&A activities in similar software companies. Hence, this study combines change management, management efficiency to that of profit maximization. We propose alternative solutions to the model of asset divestiture that incorporates the disposal of resources and firm assets as its primary mission. Given the traditional research work in M\&A, we believe that the optimal approach to M\&A is to focus on management efficiency of the acquirer firm that would be built on the union of resources, assets and culture. We shall subsequently build a framework to elaborate on our proposal.

The objective of this research is to analyze the optimal approach to M\&A given the nature of a consulting-based company in the software industry. Although the challenges of redundant resource may justify the tendency to asset divestiture in a product-based company, we hope to gain an objective, and more importantly, factual evaluation of M\&A in HiQ. Nevertheless, we narrow down the research scope to HiQ's M\&A activities done in the twenties. We aim to bring the inherent differences of a product-based and a consulting-based company and justify their differing strategic approach to M\&A. We shall also evaluate the concept of growth that may occur via M\&A or organically. In order to build a new functional framework for M\&A, insights from employees in HiQ are mingled with that of financial data of HiQ acquisitions. This new framework will be compared with the traditional literature, assessed and reviewed by relevant stakeholders. After obtaining a perspective on M\&A in HiQ, the goal would be also to align this new business framework with the vision of the company.

We have chosen the profitability ratios in our study to measure HiQ's overall efficiency in generating returns. In addition, we also take into account the cost structure of HiQ, namely the inventory and the manufacturing as well as the delivery costs as reflected by Gross profit/new sales. EBIT, also known as operating profit, that takes into account the expenses of daily business activities and is found from HiQ's income statement. Return on assets, also known as return on investment gives HiQ's ability to generate returns from investment, as reflected by net income/total assets. Likewise, return on equity measures the ratio of net income and stockholder's equity. This is, then, found in HiQ's balance sheet.

We have limited our scope of study to the product lines, customer niche, market size, geography and ownership of HiQ. Both the discussion on HiQ's M\&A and its vision are strictly bounded by the internal structure of the company. The impact of M\&A activities at different stages during the twenties is outlined by the discussions with the top management and confirmed by the annual reports. Moreover, the presentation of this case is targeted both at the technology as well as the management audience. As a matter of fact, when it comes to the methodology of research, we aim to employ design research to find the business framework for HiQ based on literature review and empirical data. Then, using various communication tools, such as company intranet and HiQ network, we hope to gain a fairly comprehensive picture of HiQ's M\&A activities in the Nordic countries. Thereafter, the conceptual design, following the framework defined by the Grounded Theory, is built on the results obtained from the previous sections. Specifically, Grounded Theory manifests via a pre-conceived theory and gradually evolving during the research process as a result of empirical research (Goulding, 2002).

\section{The Case}

HiQ's IT solutions focus on software development, quality assurance and project management to deliver high quality services with over a thousand personnel and ten locations in the Nordic countries and in Eastern Europe. Mainly, the company has operations in the ICT sector with ten subsidiaries doing business mainly in Sweden, Finland, Denmark and Russia. Recently, HiQ Finland has enhanced its market position in the software industry with big players, such as Empower, and built effective IT solutions for otherwise inhibited end-users. In addition, the joining of Frends Technology, which is currently known as HiQ ICC, offers integration solutions covering all stages of the software development cycle. Solely in the Helsinki area, HiQ Finland includes over two hundred personnel. The customer groups are divided between the game, construction and service industries. The vision of HiQ is to create a company, where people enjoy working in and with whom the customers like to cooperate with. Most of the information for the case is derived from the company data and intranet.

In terms of the business culture, HiQ puts strong emphasis on simplicity. This is because to respond to the competition in the IT industry, usability is foremost important. The complex aspect of software can be simplified to make its management more efficient. This partially explains the success that HiQ enjoys as a result of these policies. Another aspect of business culture is to work closely with the customers. This helps the consultants to better understand the customer demand in order to tailor customer-specific solutions for HiQ's long-term business partners. 
In terms of HiQ's customers, IT is central in all their business-doing, and the company plays a critical role in securing the internal framework and IT infrastructure of its customers.

The vision of HiQ, including the name that originates from High Quality, is committed to deliver a high standard in its IT solutions. HiQ also has the vision both to grow organically and through M\&A. From the year 2007 alone, HiQ Finland has bought Mobileyes, Ace Simulation Ab and TSG Test Solutions Ltd to strengthen its operation; and the technology that HiQ developed with its subsidiaries is meant to serve the business needs of its customers. In fact, the personnel in for example HiQ Finland have, on average, nine years of experience in the software engineering and business sector. The values of working are guided by professional approach, entrepreneurship, commitment and knowledge. The IT consultant corporation is constantly recruiting talented personnel to join the team.

In 2001, the operating profit for HiQ before goodwill was SEK 66 million. The mission at that time was targeted at a growth rate of $30 \%$ for the subsequent year and an operating margin before goodwill of $15 \%$. However, the economic condition had affected HiQ's financial performance in 2001. Consequently, the management board had decided to strengthen the company brand in order to reaffirm the company's position in the market. Then, 2002 marked the digital and mobile revolution. The opportunities perceived in the IT industry and low entrance rate invited more fierce competition. Competitors of HiQ are divided into fields of system development and management/strategy. In terms of the customer segments, they were divided to the telecoms, defense, finance, motor vehicles, industry \& energy, medicine and the public sector. In 2003, the trend in applications such as mobile terminals, simulators for testing and training, interactive gaming and telecoms were emerging.

In 2004, profit before goodwill (EBITA) amounted to SEK 71.6 million. During 2004, after HiQ had acquired CATS in order to expand its business to the finance industry, the company established a new subsidiary in Karlskrona. The demand for better systems continued to expand, which resulted in another growth year for HiQ. In 2005, operating profit (EBIT) amounted to SEK 148.3 million and earnings per share totaled to SEK 2.20. From the customers' side, a new order from the Swedish Materiel Administration (FMV) marked positive news for HiQ. Even a more profitable agreement from GTECH Corporation for the development work to Veikkaus earned HiQ more cash to finance the subsequent acquisitions. In general, 2005 has been fruitful for HiQ. As a result of financial success and a growth rate of $40 \%$, a dividend of SEK 2.10 per share was distributed to its shareholders. HiQ's success not only came from M\&A, the industry outlook was also booming at that time with a growth rate of approximately $5 \%$ in the Nordic IT market. Subsequently, a new testing center is established and the recruitment process continued to flourish.

Already in the year 2000, HiQ had emerging interests in the Finnish market. The company continued to grow with high profit margins complying with its vision. After receiving new order for training simulators, the focus at that time was on the telecoms, mobility and simulation technologies as well as the possibility to increase the company's influence in the respective sectors. Good brand, especially in Sweden, and long-term customer relations ensured that the subsequent acquisitions were also financially feasible. Then in 2004, the company expanded its business to Copengagen Airports $\mathrm{A} / \mathrm{S}$ increasing passenger and aircraft safety. Due to the past years' success the company managed to increase its growth and treble its operating profit and continued to expand its business to the Swedish Road Administration. Hence, the year 2004's growth strategy had one of the focus on Mälaren Valley. Due the sales opportunity bought by the acquisitions in Finland, more businesses, such as the business from GVA Finland, kept coming from the Finnish market. Subsequently, 2008 was a record year for HiQ with accelerating growth and substantially increased profits. As the success begins to accumulate, the company doubled its staff numbers and was among one of the best employers in Universum's annual "Career Barometer" survey.

The development center in Russia complemented to HiQ's project-based approach to IT. The key is to combine HiQ's specialities with that of the customers' own IT expertise; examples include Ace Interactive and Orc Software. Especially when it comes to the telecom sector, HiQ has aimed to cooperate with the related suppliers, operators and end-users. Consequently, important lessons can be drawn; an example is the establishment of the IPTV technology. In terms of the gaming industry, developing functional platforms was highly valued by HiQ's business partners. Moreover, what is evident in the automotive industry, shorter development and production cycles compels fast speed, and so far HiQ has handled well the increasing demand to deliver results. From the defense and security sector's point of view, simulation technology and communication required mastering the knowledge of different business systems. Securities trading in the financial sector have opened new opportunities for HiQ to cooperate with large international players in the financial markets. 


\section{M\&A Activites of HiQ in the Twenties}

When the company was founded in the year 1992, the vision at that time was to enlarge its business and to expand its operation in Stockholm. The telecommunication sector seemed like an alluring option. This strategy paid back when the company became listed in 1999, and hence within the seven year period since the company started its business, HiQ managed to build a strong brand in Sweden. In 2000, the IT consultant company acquired the Danish IT and Telecoms consultancy, WISE Network, with offices in Copenhagen and Århus, and hence entered the Danish software market by continuing to expand its business in the telecommunication industry. WISE is a small-scale company with twenty employees working with system development but with well-known customers such as Siemens, Motorola and Nokia. $\mathrm{HiQ}$ was mainly interested in the telecoms and mobile Internet expertise of WISE. Issuing new shares with an additional purchase price financed this acquisition. From the management point of view, the telecoms consultant Open Software Company in Gothenburg was a similar company to WISE who also developed software in the fields of GPRS, UMTS and WAP. One of the major customers of Open Software included Ericsson. The acquisition was, hence, a natural move to enhance HiQ's core business. In addition, the target firm was rather profitable with similar profit margins in line with HiQ's own. This acquisition also supported the business of its subsidiary, HiQ Väst, by strengthening the company's influence in Western Sweden. Most importantly, the expertise and customer relations offered by the target firm were well integrated to HiQ so that little asset divestiture was needed to cope with the change.

Not long after these acquisitions came a new acquisition attempt in 2002. HiQ wanted to enter the Finnish market, and consequently acquired the Finnish IT consultancy Softplan Ltd. This time, the target firm is by size larger than the previous ones with employees amounted to fifty. In addition to business in the telecom industry, this target firm also has a footstep in the public sector. One of the goals of this acquisition was to confirm HiQ's position in the Nordic market. We see that successful acquisitions do imply subsequent acquisitions and may be utilized as a growth strategy to combat industry competition, as confirmed by the literature on M\&A.

So far, quality and profitability had guided the acquisition of the target firms. As a matter of fact, the target firms in Finland had bought additional clients to HiQ including Sonera, TEKEs and Veikkaus in the forms of new business channels for HiQ. One part of the purchase price of Softplan was dependent on the financial outcomes of 2002. After a merger between HiQ Väst and HiQ Open to become HiQ Gothenburg Ab, HiQ bought the Computer and AudioTechnical Systems Ab (CATS). This target firm was similar to the previous target firms with an employee of fifty in total. However, the customer groups of CATS came from different industry sectors of finance, entertainment and gaming. At this point, market entry was no longer the focus of HiQ but the goal is business expansion to a diversified sector. As a result of profitable acquisitions, a new subsidiary called HiQ Karlskrona Ab was formed. In 2007, HiQ bought MobilEyes Ab, which had a total number of employees of sixty with ten years of experience from Symbian, and it is the expertise in Symbian that attracted HiQ's attention. Again, M\&A occurred with little asset divestiture, as HiQ was glad to combine technology of Symbian with that of its own. In addition, MobilEyes Ab had a strong hold in mobile services, and thus especially testing mobile applications, this would complement HiQ's core business. In fact, the target firm operated as an independent fully owned subsidiary of HiQ International Ab so that this acquisition would ideally strengthen HiQ' profit and earnings per share post M\&A.

In 2008, HiQ acquired TSG Test Solutions in Finland. With a similar acquisition pattern, this target firm employed seventy consultants specialized in quality assurance with sound management morale and profitable business. Post M\&A it also operated as a fully owned subsidiary of HiQ. At the same year, the company also acquired ACE Simulation $\mathrm{Ab}$ in Linköping. ACE was doing business with international conglomerates in the automotive and defense sectors, and this offered HiQ the possibility to knot big deals with the initial customers of ACE. In addition, ACE offered a niche market to HiQ in Linköping. This target firm, then, operated as a fully owned subsidiary of HiQ International $\mathrm{Ab}$. We may conclude here that if TSG was acquired mostly due to its expertise in quality assurance, then ACE was acquired mainly because of its customer relations.

The most recent acquisition was Frends Technology Ltd. that had expertise in process integration with customers in the retail and manufacturing industry. This acquisition further consolidated HiQ's position in Finland. In 2010, Frends was awarded the Country Partner of the Year by Microsoft.. Frends technology is expected to strengthen HiQ's income and earnings per share. At the same year HiQ Softplan and HiQ Quality Services were merged. We see a pattern both in the acquisition as well as in the merger side of HiQ. This is closely linked with HiQ's profit maximization and growth motives. In addition, the acquisition of Frends Technology also confirmed our initial assumption that not all target firms are unprofitable by nature. HiQ is, in fact, interested in profitable target firms that have expertise of their own and operate successfully in the market niche with stable customer relations. 
In 2010, HiQ's operating profit (EBIT) of SEK 156 million equates to an operating margin of $14 \%$, implying a growth of $5 \%$, can be partially explained by the opportunities bought by the global trend, such as social networks, cloud computing and mobile applications. The rapid advancement of technology also brings the vital need to build reliable IT architectures. Since we are interested in the situation of IT consultancy services and the related market, for example in Öresund, the Nordic mobile phone manufactures had their own challenges, and this, in turn, affected the overall customer market in the software industry. For HiQ, IT projects were the building pillars to overcome the changing market conditions. Going to other industries such as finance and retail also opened attractive financial opportunities for HiQ. In Finland, the acquisition of Frends Technology had the aim to enlarge HiQ's business to the process integration market. One of the main benefits was the existing customer base that Frends had bought to HiQ. At the same time in Sweden, organic growth was evident partially due to the brand, as can be seen by HiQ winning Sweden's best IT consultancy firm by the Swedish business journal Veckans Affärer's ranking of IT consultancies. Since the company was found, it had an average operating margin of $15 \%$ and an average growth of $24 \%$.

HiQ now operates in ten subsidies located in Sweden, Denmark, Finland and Russia. When HiQ Kobenhavn was acquired, its primary function was to strengthening the business in the telecom industry. HiQ Russia, then, offers expertise in software development and exists as a development center. HiQ Finland, as a result of the acquisition, functions as a base for quality assurance and IT solutions. Likewise, Frends Technology was acquired to enlarge HiQ's service offerings in the integration sector. HiQ Ace, then, specializes in simulation technology for the automotive and telecom industry, and the telecom industry has remained a profitable sector for HiQ. These acquisitions illustrated the importance of combining the core business of the target firm to that of the acquirer firm without heavy asset divestiture in order to expand the expertise and product offerings of the new company. Scale economies and growth through M\&A was definitely in the vision of HiQ from the onset.

In terms of the industry, HiQ belongs to the 62 software, consulting and related services industry under the classification of information and telecommunication in Finland. Specifically, the sub-groups of this industry are defined as software and consulting; software design and implementation; IT consulting; computing and software maintenance; and related software services according to TOL 2008, which is based on the EU's industry classification NACE that is a result of ISIC (International Standard Classification of All Economic Activities). We are especially interested in the software industry development. In fact, the revenue of the software and consulting industry was higher in the year 2008 as compared to 2009. We see that the revenue of the information service industry had also grown steadily in 2008 from 2006. That is, the software and consulting industry had performed relatively well during this period of time despite the financial crises. No doubt the industry development itself affected HiQ's performance; for example, in the retail sector given the growth in commerce, this has bought new customer bases and projects for HiQ both in the Nordic region and internationally. Yet, the financial crisis had influenced the growth of the industry as a whole, especially towards the end of the year 2008, as shown by the financial performance of HiQ during the same year.

As influenced by the development of the financial market and consumer confidence, the revenue of the information service industry had declined $3 \%$ since 2008 . In $2008,36 \%$ of the revenue came from the IT sector whereas $30 \%$ came from the telecommunication sector. The telecom industry has been one of most profitable sector for HiQ. This also explains HiQ's rapid acquisitions that occurred in the telecom industry. In fact, one of the primary aims of M\&A is to expand HiQ's business in the Nordic countries and strengthening its core business given it a strong hold in the software market. However, the software and consulting industry, in general, was badly hit and resulted in a decline of revenue from the previous year. In fact, the growth already slowed down to zero towards the end of 2008. In spite of the industry outlook, HiQ continued its growth and strengthening its position especially in the Finnish market. The later acquisitions had, then, improved the financial performance of HiQ from the year 2008 onwards. These data were obtained from Suomen virallinen tilasto (SVT): Informaatiopalvelujen tilinpäätöstilasto [verkkojulkaisu].

M\&A is closely related to concepts of profit margin, process management and market position of the acquirer firm. From the beginning of nineties, HiQ already had rapid growth in its vision to become a big player in the software industry. In most cases, the target firm was limited to a comparatively medium size before the acquisition took place. Based on the example target firms of HiQ, they have approximately thirty to sixty employees in total. Likewise, the target firm of HiQ mostly had profitable business and sound management principles before the acquisition. They had a good customer base and complemented HiQ's core business. A good example is Frends Technology that was acquired in the year 2010. In addition, HiQ was also interested to actualize the future value of the target firms by the expected rate of return. In terms of Frends Technology, HiQ Finland gained tax advantages from the acquisition, which positively affect HiQ's earnings per share from the onset. 


\section{Alternative Framework of $M \& A$}

The scale efficiency theory implies the disposal of redundant resources and the elimination of repeated processes. (Weber et al., 2011) Hence, when there is a high degree of strategic similarity between the acquirer and the target firm, scale efficiency would require the sale of units from the target firms that work on similar businesses. Anand and Singh (1997) have shown the scale efficiency theory to correlate with the selling of assets, shutting down of factories and reduction of work force, improving the overall profitability of the new firm. According to O'Shaughnessy and Flanagan (1998), overlapping businesses trigger asset divestiture even in stable industries. Firms operating in the same industry with common markets result in higher strategic gains of scale efficiency than vice versa. As a matter of fact, firms of such apply scale efficiency through alignment of resources and prefer to share rather than combine businesses.

Given the strategic similarity of the acquirer and target firm, in light of cost minimization, both the acquirer and the target firm are traditionally assumed to allocate their resources according to the scale efficiency theory. (Lakshman, 2011) Yet, given the benefits of the target firm, we believe that asset divestiture and resource redeployment through disposal in existing assets and processes may even impact negatively on the acquirer firm diminishing the benefits of M\&A. This is because the acquirer firm may attain growth without the target firm, and hence it is the different business morale in the target firm that makes it valuable to the acquirer firm. When HiQ acquired TSG in 2008, the target firm already possessed sound management practices that may, nevertheless, differ from the management practices of HiQ. In addition, the personnel from TSG had held management positions in the past, and hence were seen as assets to HiQ. Consequently, the company decided to integrate this target firm by combining different business practices from TSG and promoting the personnel from TSG to the management board of HiQ.

We believe that one of the primary reasons behind asset divesture in a product-based company include its strategic alliance. Yet, a list of benefits of M\&A based on strategic independence in a consulting-based company includes:

- Competence in terms of intangible assets and knowledge accrue from the target firm to the acquiring firm

- Intellectual property rights and related technologies from the target firm serve as innovative technology platforms for the acquiring firm

- In term of human resource, capable personnel is of vital importance to a consulting-based company

- Growth from M\&A is much more effective to achieve scale economies than organic growth

Given the differing resource structure of the acquirer and the target firm, optimal resource allocation takes different forms prior, during and post M\&A given conflicting management incentives. It is interesting to note that strategic similarity between the target and acquirer firm, such as the case with most of HiQ's acquisitions, did not automatically imply a high level of asset divestiture in this case. On the contrary, HiQ has chosen to let the target firm to run as a fully owned subsidiary to remain their core business and even supplemented their product offerings. A good example is MobileEyes from the M\&A in 2007. Moreover, in terms of risk management in M\&A, the management board of HiQ also viewed efficiency in light of long run benefits.

Business dynamics bring out the complexity of M\&A and take into account the positions of the acquirer and the target firm as individual business units that have their own operating principals. According to Galunic and Rodan (1998) M\&A offers innovation when the business practices of the acquirer and target firm are aligned in the new company. Consequently, they would, in ideal cases, complement each other and offer each other advantages for the general well-being of the new firm. This combination of expertise would then help the new firm to better face competitions in the market and in offering better services to the customers. Both resources, process and management practices from these two firms can benefit each other as a result of M\&A. (Baker et al., 2012) Nevertheless, the question remains the degree of integration. In other words, we want to keep the sound management practice of the target firm and unite that with the acquirer firm, while still remain efficient.

Prior to M\&A both the acquirer and the target firm follow a different set of management principles on resource allocation. (Akhavein et al., 1997) During M\&A if the acquirer firm would adopt a high level of asset divestiture for the purpose of cost minimization to get rid of redundant resources in the target firm, this often results in stress, coping problems and a loss of working morale in the target firm. That is, the acquirer firm may apply management theory to the target firm in which the employees of the target firm find hard to adopt. (Anand and Delios, 2002) Yet, one of the most important assets of the target firm stems from its working morale. Therefore, the organizational asset, being one of the most valuable assets, can be sustained when the acquirer firm respects the business culture of the target firm. Of course, the acquire firm may possess management morale that also benefits the target firm. In this case, the change needs time. Consequently, resource allocation, whether organizational assets or human capital, 
would be ideally based on the combination of best practices from both. This is what happened with HiQ's M\&A activity of Softplan in 2002.

It is common to think of management in abstract and efficiency as reduction. Instead, we would propose to view M\&A in such a way that instead of disposal and sales, we have reorganization and redeployment. This implies that M\&A would aim to position the two companies according to their strengths, while sustaining most of their original assets. Specifically, human capital can be trained and repositioned. Resources can be furnished and redeployed. Customer groups can be enhanced and expanded. Subsequently, M\&A would allow an instant growth and savings from recruitment. One might argue that a high level of strategic similarity between the acquirer and the target firm, would justify the tendency for asset divestiture. However, these very similar assets and practices can be utilized to enhance each other. In value creation, this strategy can also be used to beat competition. Consequently, economies of scale are gained when the two companies combine to one new company without diminishing their sizes post M\&A. It is also easier for companies operating in similar fashion to unite their businesses instead of vice versa. This is also evident in the M\&A history of $\mathrm{HiQ}$, when the company had preset criteria with regard to the industry of the target firm. In this case business transformation between companies of strategic similarity generally occurs more smoothly than firms with divergent strategies (Feng, 2011).

Traditional literature would encourage the establishment of common technical and organizational practices among the acquirer and the target firm. (Grossman and Helpman, 2004) However, investing in common practices entails additional costs, which can be avoided if the acquirer firm reaches consensus with the target in aligning their resources and processes while still respect their strategic differences. In other words, M\&A would support the firms to exploit what was previously perceived as no value using new tools in sharing experiences. As the case with HiQ, one important goals of M\&A was to strengthen HiQ's position in the Nordic markets and open up new customer niches, and hence the company was happy to support the target firm operating rather independently sustaining their existing customer base. This would a better strategy than formulating a brand new subsidiary, as seen with HiQ East and HiQ A/S. Management efficiency, thus, in this case correlates with resource redeployment and the integration of all assets to its best potential.

While it is true that the target firm may possess resources and processes that resemble that of the acquirer firm, and hence may seem redundant. These very resources and processes may be redeployed and trained for better usage. In terms of human resources, one of the motives of M\&A is to gain the competence and expertise of the target firm. A good example is the M\&A of MobileEyes Ab that had bought HiQ the expertise of Symbian, which originally was the core value of this target firm. Therefore, if the management board would focus on positioning resources to its best usage, then previous shortages are complement by fresh inputs. One of the strong motivations to do so is the profit maximization goal of the acquirer firm. By profit maximization, we mean value creation. Logically the acquirer firm would adopt any policy that creates value. When speaking of assets, resources and human capital, they all have potential to create values for the acquirer firm. Hence, by combining the management efficiency incentives with that of the profit maximization incentives, the acquirer firm would aim to actualize the potential of all assets in the target firm. Moreover, there does not need to be a trade-off between these incentives. This is because anything that creates value may also save costs.

One of the purposes of M\&A is to understand the subsequent resource allocation and behavior of the acquirer and the target firm. (Stiebale and Reize, 2011) The foremost approach to M\&A in a product-based firm would conform to resource redeployment in the forms of asset divestiture and disposal of resources. However, in a consulting-based company, the management efficiency and profit maximization goals would be under-achieved post asset divestiture and disposal of resources due to the complex business dynamics of the acquirer and the target firm. Consequently, the benefits of M\&A are greatly reduced. Subsequently, as the case with HiQ, the level of asset divestiture is lower than otherwise expected for a product-based company. As a matter of fact, HiQ has integrated many of its target firms as a subsidiary of the parent firm, given the examples of MobileEyes in 2007, Ace Simulation in 2008 and TSG in 2008.

The technological advancement and globalization as well as the demand for fast information access and the emphasis on size have all propelled the need for more M\&A activities in order to compete in the market for more market share, or otherwise as a strategy to conquer new markets. We see that a positive M\&A experience would invite more M\&A activities in the future, as in the case of HiQ, which had, at most, two acquisitions per year in 2008, strengthening the core business of the acquirer firm and enhancing its market position as a solid player. On the other hand, a failure to integrate M\&A into the existing operation and management policies of the acquirer firm would be destructive weakening its chance of survival. The shareholders suffer, as new acquisitions are often initiated by issuing new 
shares resulting in share dilution. We conclude that our M\&A framework deals with three important concepts: resource allocation, management efficiency and profit maximization. Given resource allocation prior, during and post M\&A there indeed exist differences between the acquirer and the target firm in incentives, interests and motivation. (Houston et al., 2001) Therefore, their relationships, attitudes and cultures would, in ideal cases, be mutually respected. Moreover, resource redeployment is a form of resource allocation that may or may not include the disposal of assets depending on the nature of the firm. Therefore, the primary motive of management efficiency for resource allocation still relies on the fundamental operating principal of business; that is, profit maximization that takes different forms depending on whether we are talking about a product-based or a consulting-based company.

\section{Conclusion and Discussion}

HiQ started in 1992 when Statyetten Konsult Ab and the subsidiary Approve Ab are founded. Simulation technology was the core business back then. The parent company was renamed to HiQ International Ab, and subsequently, subsidiaries were formed in Gothenburg and Oslo. HiQ, then, got listed in the Stockholm stock market. Soon after that, the company continued to acquire two new subsidiaries, namely the Danish HiQ Wise and the HiQ Open from Gothenburg. The business came to Finland with the subsidiary called HiQ East Ltd. M\&A activities continued whereby Softplan Ltd was acquired. In Lund, the new subsidiary was formed, namely HiQ Skåne Ab, while at the same time HiQ East and HiQ A/S were terminated. Then in 2003, HiQ Väst and HiQ Open were merged to become HiQ Gothenburg Ab. On the other hand, when the Computer and Audio-Technical Systems Ab were bought as part of the growth strategies, a new subsidiary was formed called HiQ Karlskrona Ab. In 2007, MobilEyes Ab were bought despite the previous rapid acquisitions of similar-sized software companies. Subsequently, Ace Simulation, TSG Test Solutions were also bought in order to enlarge HiQ's impact in Finland. Finally, in the year 2010, HiQ Softplan and HiQ Quality Services were merged to become HiQ Finland. We see that an integrate part of HiQ's success is built on top of affluent M\&A activities. We also believe that these very strategies also constitute important growth and profit maximization strategies for HiQ.

One of the primary goals of this research is question the passive role of the target firm and the power distribution between the acquirer and the target firm. Resource allocation and management efficiency remains the attention focus in the research of M\&A. The traditional viewpoint would suggest that resource redeployment is mainly concerned with the disposal of assets and redundant resources. However, it is in the interests of the acquirer firm to actualize the potential of the target firm and benefit from the strategic alliance through union of business practices. Subsequently, one of the goals of M\&A is also to retain the management efficiency of the target firm. While the disposal of physical and human resources of the target firm may have been an automatic response of solving the problem of redundancy and strategic similarity, we believe that the resources of the target firm could be utilized to complement or supplement the management efficiency of the acquirer firm.

As a result of change management that becomes more apparent when companies decide to cooperate in face of global competition, the approach of M\&A deserves a new perspective. If we assume that the decision making of the acquirer firm and its managerial policies directly affect the target firm and the power struggle is rather passive from the point of view of the target firm, the potential of the target firm is not fully actualized but instead is disposed in face of M\&A as seemingly a result of the profit maximization incentive of the acquirer firm. Given the purpose of M\&A, as opposed to organic growth, asset divestiture in the target firm may trigger additional costs in the later stage of growth in the acquirer firm. In some cases, innovation, new stream of knowledge, fresh look and change for its own merit can all be part of the benefits of M\&A. As with HiQ, the company had incentives to grow internationally either to a new market or to a new industry already prior M\&A, such as the acquisition cases of WISE Network in 2000, and hence M\&A was more of a tool to gain new expertise, recognition and customer niches. In addition, if the target firm shows profitable performance prior to M\&A, it would make sense for the acquirer firm to integrate the management morale of the target firm without a high level of asset divestiture. For example, the customer base and operational policies of both HiQ and the target firm have mainly stayed the same prior, during and post M\&A. This is especially evident in the M\&A of Open Software in 2000, Ace Simulation in 2008 and Frends Technology in 2010.

The acquirer firm could influence either directly or indirectly the target firm's product, process, tool and market practices as a result of M\&A. In an ideal case, the M\&A activity would bring new customer groups and new market opportunity, reinforcing the market position of the acquirer firm in the industry. Nevertheless, the asymmetric manner in which management efficiency is affected in M\&A between the acquirer and the target firm can by explained by the different management roles during this process. Given that resource allocation in M\&A is partially affected by the motive for scale efficiency; the differences in the goals of the acquirer and the target firm stems from 
their conflicting incentives. In order to test this difference, the means test developed by Kmenta (1986) compares the effects of resource allocation according to the scale efficiency theory between the acquirer and the target firm. The application of this method was also used by Miner et al. (1990) and Baum and Oliver (1996). The results show that the impacts of the scale efficiency theory on resource allocation were stronger in the acquirer firm than in the target firm. Therefore, the management board of the acquirer firm, taking the initiative and active role in M\&A, often implements resource redeployment schemes that are assumed to benefit their own operations as a starting point. (Boubarker and Mezhound, 2011) Nevertheless, the knowledge of the target firm concerning their business processes and working culture would gain them decision power in the resource redeployment scheme. Consequently, while the acquirer firm would aim to profit maximization from the M\&A process, it is also in their interests to allocate the resources of the target firm according to the management efficiency theory.

It seems that HiQ has often aimed to buy independent successful firms and cut costs to support their independence post M\&A. Thereafter, the strategy has been to raise the sales per consultant of the target firm. The industry of the target firm has been small-sized software companies. The operational effectiveness of HiQ can be concluded by the historical performance of its M\&A activities the business culture of the parent company that was formed in already in the year 1998, namely the vision for rapid growth. Given the hectic software industry where competition is fierce and the entry of market is low, a consulting-based company like HiQ is more prone to build its profit maximization goals on strategic alliance rather than a high level of asset divestiture, in contrary to a product-based company. This result is particularly relevant for future M\&A activities in HiQ and offers new insights for M\&A strategies of similar software companies. Finally, confirmation of theories with empirical data and comparison studies have been generally acknowledged as bringing values to the top management in their decision-making about the business culture as well as the daily operations of the existing business units.

\section{References}

Adel, B., \& Mediha, M. (2011). Impact of managerial ownership on operational performance of IPO firms: French context. International Journal of Management Science and Engineering Management, 6(3), 191-197.

Akhavein, J. D., Allen N. B., \& David B. H. (1997). The Effects of Megamergers on Efficiency and Prices: Evidence from a Bank Profit Function. Review of Industrial Organization, 12, 95-139. http://dx.doi.org/10.1023/A:1007760924829

Allen, L., \& Anoop, R. (1996). Operational Efficiency in Banking: An International Comparison. Journal of Banking and Finance, 18(6), 655-672. http://dx.doi.org/10.1016/0378-4266(95)00026-7

Altunbas, Yener, P. M., \& John T. (1997). Big-Bank Mergers in Europe: An Analysis of the Cost Implications. Economica, 64(264), 317-329. http://dx.doi.org/10.1111/1468-0335.00080

Anand, J., \& Delios, A. (2002). Absolute and relative resources as determinants of international acquisitions. Strategic Management Journal, 23, 119-134. http://dx.doi.org/10.1002/smj.215

Baker, M., Pan, X., \& Wurgler, J. (2012). The effect of reference point prices on mergers and acquisitions. Journal of Financial Economics, 106(1), 49-71. http://dx.doi.org/10.1016/j.jfineco.2012.04.010

Feng, Z. Q. (2011). Financial risks from three dimensions and risk identification model of enterprise. International Journal of Management Science and Engineering Management, 6(1), 71-80.

Gregor, A., Mitchell, M., \& Stafford, E. (2001). New Evidence and Perspectives on mergers. Journal of Economic Perspectives, 15(2), 103-120. http://dx.doi.org/10.1257/jep.15.2.103

Grossman, G., \& Helpman, E. (2004). Managerial incentives and the international organization of production. Journal of International Economics, 63, 237-262. http://dx.doi.org/10.1016/S0022-1996(03)00072-2

HiQ annual reports. (2000-2010). HiQ company: http://hiq.se

Houston, J. F., \& Ryngaert M. D. (2001). Where Do Merger Gains Come From? Bank Mergers from the Perspective of Insiders and Outsiders. Journal of Financial Economics, 60(2), 285-331. http://dx.doi.org/10.1016/S0304-405X(01)00046-0

Lakshman, C. (2011). Postacquisition cultural integration in mergers \& acquisitions: A knowledge-based approach. Human Resource Management, 50(5), 605-623. http://dx.doi.org/10.1002/hrm.20447

Nishihara, M., \& Shibata, T. (2010). Strategic investment with debt financing. International Journal of Management Science and Engineering Management, 5(1), 3-14. 
Stiebale, J., \& Reize, F. (2011). The Impact of FDI through mergers and acquisitions on innovation in target firms. International Journal of Industrial Organization, $29(2), \quad$ 155-167. http://dx.doi.org/10.1016/j.jindorg.2010.06.003

$\mathrm{Su}, \mathrm{K}$., Yang, S., \& Yang, B. (2010). Ultimate ownership and firm performance: evidence from Chinese private listed firms. International Journal of Management Science and Engineering Management, 5(3), 182-191.

Suomen virallinen tilasto (SVT): Informaatiopalvelujen tilinpäätöstilasto [verkkojulkaisu]. ISSN=1798-3789. 2008, Informaatiopalvelut 2008. Helsinki: Tilastokeskus [viitattu: 27.7.2011]. Saantitapa: http://tilastokeskus.fi/til/iptp/2008/iptp_2008_2009-12-30_kat_001_fi.html

Weber, Y., Tarba, S. Y., \& Bachar, Z. R. (2011). Mergers and acquisitions performance paradox: the mediating role of integration approach. European Journal of International Management, 5(4), 373-393. http://dx.doi.org/10.1504/EJIM.2011.040911

\section{Note}

Note 1. The author would like to heartily thank the personnel in HiQ for revealing their valuable insights on the topic. Since the author was originally positioned in Frends Technology that was the target firm of M\&A in the year 2010, the M\&A process and transition was witnessed from an employee's point of view. 